There is a variable and widespread species of Aymnosporia ( $G$. senegalensis), and the usual species of Christ's thorn (Ziziphus), a species of Grewia (G. populifolia, Vahl), common farther south and extending eastward to India, seven species of Tamarix, and a few rock-roses (Helianthemum). The myrtle family is represented by an endemic species, Myrtus Nivelii, Batt. and Trab., and there is also a native olive, Olea Laperrini, Batt. et. Trab., about twelve feet high with a trunk eighteen inches in diameter, very closely related to the European olive, Olea europaea.

It may be said, therefore, that the ligneous plants of the Hoggar region show affinities with both the Mediterranean and tropical African floras.

The herbaceous vegetation is composed mainly of the most advanced families or of advanced genera which are widely spread from Morocco to Arabia and Sind. The dominant families are the Compositæ (about 60 species), Cruciferæ (35 species), Papilionaceæ (31 species), Chenopodiaceæ (22 species), Caryophyllaceæ (18 species), Boraginaceæ (13 species), Umbelliferæ (10 species), Labiatæ (10 species).

There are as many as ten species of Asclepiadacex, several of them widely spread from North Africa to as far as India; but there are two endemics, Glossonema Gautieri, Batt. and Trab. and Caralluma venenosa, Maire.

The family Malvaceæ, so common in the savannah region farther south, is very poorly represented, and Acanthaceæ not at all.

The flora of the Tibesti Mountain mass, so far as known, is poorer than that of the Hoggar. Four botanical collections have been made, by Nachtigal, General Tilho, Dalloni and Tarrieux.
The range is volcanic and reaches an altitude of more than $10,000 \mathrm{ft}$., culminating in the peak called Emi Koussi. The best collection so far made is that of Dalloni, who reached an altitude of 7,700 ft., but in a poor season after prolonged drought. It is possible, therefore, that during a good season many more flowering plants would be discovered. The number of ferns and flowering plants recorded by Maire is 159 .

Ephedra is represented by an endemic species (E. Tilhoana, Maire), and an endemic variety of E. altissima, Desf. (var. tibestica, Maire). The typical form of the latter is found also in the Hoggar and in North Africa. The Hoggar eypress has so far not been observed; but the interesting Pentzia, P. Monodiana, mentioned above, was collected by Tilho at about $9,000 \mathrm{ft}$. altitude. It is browsed by goats and donkeys.

A shrub common in tropical Africa, Phyllanthus reticulatus, Poir. (Euphorbiaceæ), is rare in Tibesti. The beautiful crucifer of the Hoggar, Moricandia arvensis var. garamantum, is absent; but there are two rock roses common to both mountain groups. Another interesting composite has been discovered in the Tibesti, besides the Pentzia, namely Tibestina, Maire, a new genus of the thistle tribe, and two interesting new Papilionaceæ, Dichilus Dallonianus, Maire, and Lotus tibesticus, Maire, the former claimed by its author to be of South African affinity, the latter allied to species from the Atlantic Islands.

Prof. Maire's two papers are notable contributions to our knowledge of the flora of the Sahara, and botanists will await with keen anticipation his third paper dealing with its phytogeography and a study of its vegetation.

\title{
Obituary
}

Prof, I. P. Pavlov, For.Mem.R.S.

PROF. IVAN P. PAVLOV, who died on February 27, was by common consent the doyen of physiologists. This position he achieved by reason of his great age, his great distinction, and his great vitality. His age was such-he celebrated his eighty-fifth birthday in 1934 - that few living workers in Great Britain even came within measurable distance of being his contemporaries, whilst to most, Pavlov's early working years appeared to go back into a distant past. Yet even apart from that, Pavlov was to English workers a somewhat remote figure until within the post-War period*. This perhaps was because he was not a particularly good linguist : he spoke Germon and had worked in Germany, but he was never at home in English.

- Notwithstanding that Pavlov visited Cambridge in 1912 to receive an honorary degree.
Nevertheless, though not well known personally in England, Pavlov's name became one with which to conjure in the early nineties of last century as the result of his work on digestion. His book "The Physiology of the Digestive Glands" produced a profound impression throughout the scientific world, and at once placed Pavlov not only in the first rank of physiologists, but also of scientific men of whatever kind. So far as the technical side of Pavlov's work on digestion was concerned, the great progress which he made was due to his recognition of two principles : first, that the deductions from his experiments would be misleading if the animals on which those experiments were made were in pain or even in a disturbed mental condition; and secondly, that no better results could be obtained if the animals were under a general anæsthetic. Thus Pavlov set himself, by ingenious surgical methods, so to dispose the parts 
of his experimental animals that, while the relevant organs were accessible, the animals were happy and in their usual health. In this way he observed the properties of the principal digestive secretions, the conditions under which those secretions took place, and their interrelation.

Much of the ground has been covered since on man; but the whole of it never can be on a single patient or at a single time, because the repetition on man of some one observation of Pavlov's depends upon the chance of a patient at the same time being the victim of some unusual accident and falling into the hands of a doctor with the scientific ability to profit by the occasion. Pavlov's work on dogs, the items of which form a continuous whole, can be checked on man-one item on one patient say in Chicago, another on a different patient in Boston, a third in London, and so on-everything being referred to the original work as to a builder's line. Sometimes complete identity is found between the human findings and the canine and sometimes a species-difference; but though there is nothing very new in the evils accidents involve, the knowledge to be derived from them is duly threaded together on the basis of Pavlov's work.

Another and entirely novel aspect of Pavlov's work on the digestive glands must be mentioned, and one entirely in keeping with his own character; it had a very human side. Not only was there close and correct thinking; not only tables of concentrations of this and that; but at the end there appeared a reasoned basis for age-old human customs : for why the menu was as it was; for why the hors d'cuvres should precede the soup and the soup the joint. Perhaps most important of all, a new light was shed upon dietetics, no less than that-other things being equal-a condiment was likely to be digestible in proportion as it appealed to the palate. This, at the end of the Victorian era, amounted almost to a revolution. It was on the basis of his work on the digestive glands that Pavlov, shortly after the establishment of the Nobel Foundation, was the recipient of the Nobel Prize for Physiology and Medicine (1904).

Since the Great War, Pavlov has visited Englishspeaking countries on a number of occasions, the most recent of which was the Neurological Congress in London last summer. In 1928, he gave the Croonian Lecture at the Royal Society. Naturally, to those who knew him only as a researcher of great eminence, it was a matter of no small interest to discover what manner of personality this distinguished visitor possessed. At once the appeal which Pavlov had already made to the intellect spread no less powerfully to the heart. Pavlov became an object of affection to all with whom he came in contact. He came, of course, in very unusual circumstances: his country had passed through perhaps the most searching revolution of all time, and it had emerged the champion of simplicity; its creed that the figure of a man was to be measured by his personality and not by the circumstances of his birth. Pavlov was in a sense cast for this role: on great occasions, when others were adorned with the panoply of circumstance, Pavlov, the greatest of them all, stood up in the simple suit of rough blue serge enjoined by the canons of the Soviet, and elevated that dress to a uniform more dignified than all the rest. He was a soldierly figure, rather spare, but vibrant with energy, the embodiment of dignity; but ere long the dignity expanded into benignity.

An incident may be recalled which at once illustrates Pavlov's concentration and his sense of humour. In the year 1928, Pavlov gave a lecture to a packed audience of Cambridge undergraduates. The scheme was as follows: Pavlov was to lecture in Russian for half a minute at a time and Dr. G. Anrep then to translate. After perhaps three such cycles, Pavlov got so engrossed in his subject as quite to forget that his audience did not understand what he was saying. On and on he went for perhaps five minutes - then it dawned upon him. He wrung his hands, he burst into peals of laughter, the whole audience rockedPavlov had completely won the undergraduate heart.

Little need be said of the second phase of Pavlov's work, that on conditioned reflexes : it is well known and has been fully dealt with in NATURE (Jan. 3, 1925) by the late Prof. Starling, which was accompanied by a photogravure portrait of Pavlov. Among the main conceptions of his work on the higher nervous centres are: that behaviour depends largely upon the balancing of excitatory and inhibitory activities - 'do's' and 'don'ts' ; that both may be 'conditioned', that is, associated by habit with some stimulus which appears to have little connexion with the action (as, for example, if a light is always turned out three minutes before a dog is given food, the dog will ultimately secrete saliva three minutes after the illumination whether the food be given or no); that owing to temperamental differences, some creatures will react more readily to the positive and others of the inhibitory stimuli; that sleep is a form of conditioned inhibition; that the even balancing of conditioned reflexes urging action in opposite direc. tions may produce a conflict and ultimately a violent neurosis.

Perhaps the most arresting fact about Pavlov's later years was the enormous prestige which he possessed in his own country. Any such crude state. ment as that Pavlov was in an exalted position because the mechanistic trend of his work on conditioned reflexes furnished a prop for irreligion, seems to do less than justice both to Pavlov and to the Soviet. In proportion as a culture writes off the supernatural, it will regard the highest study of mankind as man, and the highest phases of human study as those of the nature and products of his intellect. Such studies are treated with the greatest emphasis in the Soviet Union. The marvellous col. lections in the Hermitage Museum at Ieningrad of Scythian and Iranian art would not be cherished as they are except as manifestations of the develop. ment of the human mind. By a stroke of fate, it happened that the man who had done more than any other to analyse experimentally the workings of the intellect coincided in time and place with a culture which elevated that mind to a place accorded elsewhere to the supernatural. 
Scientific distinction alone would not have given Pavlov the influence which he possessed. To distinction was added a fervent love for Russia and complete loyalty to her institutions. Not that Pavlov was a propagandist. So far as I know he took no part in polities, and that coupled with the fact that he was without guile probably contributed in no small degree to the trust which his Government placed in him.

The impression with which to end this slight tribute is that of Pavlov's home life. As he loved his country, so he loved his family. His tastes were simple; he loved digging the soil and spent his leisure largely in gardening. The prospect of, say, some new seeds filled him with enthusiasm, but they would be the seeds of some simple colourful species - for example, a new kind of poppy.

No better example than Pavlov could be quoted to illustrate the kinship between simplicity and greatness. JOSEPH BARCROFT.

\section{Dr. G. T. Prior, F.R.S.}

George Thurland Prior, keeper of minerals in the British Museum from 1909 until 1927, died on March 7 at the age of seventy-three years. He went to the Department of Minerals at the Museum at the close of a successful career at Magdalen College, Oxford, where he had gained a demyship in natural science in 1881, and a first class in the Honour School in Chemistry (1885) and Physics (1886). He studied for a short time in Germany, and entered the British Museum in 1887 a few years after the opening of the new building for the Natural History Departments.

Prior's first duties at the Museum were concerned entirely with the chemical analyses of minerals, work which had hitherto been done almost entirely by Dr. Walter Flight. He was a born chemist, and excelled in the careful manipulation of small quantities of material and in the patience with which he selected and prepared his materials for analysis.

The value of Prior's work was soon recognised, and in 1900 he was awarded the Wollaston Fund by the Geological Society of London. At that time, he had begun to be interested in petrography, and in his thanks to the president of the Geological Society he spoke of his intention to make his mineralogy more geological in its character. This promise was speedily carried out, and there followed a series of papers on the petrography of the volcanic rocks of British East Africa and the antarctic continent, based on the collection of J. W. Gregory in Kenya Colony, and on those made on numerous expeditions to the Antarctic. His account of the rocks collected by H. T. Ferrar during Scott's Discovery expedition of 1901-4, being printed only in a British Museum publication, is less widely known than his numerous papers in the Mineralogical Magazine.

Prior's work in petrography is distinguished by the skill with which from among the masses of material in the rock collections at the British Museum he selected the important and interesting specimens, and clearly and briefly described their characters. His pioneer work on rocks from remote regions suggested to later workers many lines of fruitful study.

On the appointment of Sir Lazarus Fletcher to the directorship of the Natural History Museum, Prior became Keeper of Minerals. Almost at once he took up the work on meteorites begun in the Museum by Story-Maskelyne and continued by Fletcher. Here again his complete mastery of inorganic analysis led to the production of a series of chemical studies of meteorites, on which he based a classification of the greatest importance. He showed that there is a very definite and significant relation between the ratio of iron to nickel in the nickel-iron and the ratio of magnesia to ferrous oxide in the ferromagnesian silicates in a meteorite, a relation possibly accounted for by progressive oxidation acting on a common magma from which meteorites are derived.

During his keepership, Prior revised Fletcher's "Introduction to the Study of Rocks", rewrote the British Museum "Guide to the Collection of Meteorites" and completed a comprehensive catalogue of the meteorites in the British Museum collection, perhaps the finest in the world. The conclusion of this work was fittingly acknowledged by the award of the Murchison Medal of the Geological Society in 1927.

Prior's lovable, gentle character endeared him alike to friends and colleagues, and his published papers, numerous though they are, form only a part of his work, so much of which was devoted to the help of others who came constantly to seek his advice and assistance. He was general secretary from 1909 until 1927 and president in 1927-30 of the Mineralogical Society, and a vice-president of the Geological Society of London from 1921 until 1923. He was elected a fellow of the Royal Society in 1912. He married in 1914 Esther Louisa Alberta, daughter of the late Mr. Henry Cole of Cork, who survives him together with two daughters.

W. C.S.

According to a note in the Chinese Journal of Physiology, 1935, Eric Reid, of the Henry Lester Institute of Medical Research, Shanghai, died there on November 24, 1935. Reid was born on October 3, 1906, at Gamrie, in Banffshire, Scotland. In 1929-32 he worked at the Rowett Research Institute, Aberdeen, upon the absorption of foodstuffs, chiefly carbohydrates and phosphates, from the alimentary canal. Going to Shanghai in 1933, he undertook a study of basic facts regarding the composition of local foodstuffs, general dietaries and infant feeding and much of this programme was accomplished.

WE regret to announce the following deaths :

Mr. Harold Brown, O.B.E., for the past ten years principal of the Plant and Animal Products Depart. ment of the Imperial Institute.

Prof. J. S. Haldane, C.H., F.R.S., director of the Mining Research Laboratory and honorary professor in the University of Birmingham, at midnight on March 14-15, aged seventy-five years. 